\title{
Diários de Aula: reflexões sobre a prática docente no ensino fundamental
}

ARTIGO

Class Journals: reflections on the teaching practice in elementary school

Dirce Hechler Herbertza

\section{Editores}

Maria Inês Côrte Vitoria PUCRS, Brasil

Pricila Kohls dos Santos PUCRS, Brasil

\section{Equipe Editorial}

Carla Spagnolo PUCRS, RS, Brasil

Marcelo Oliveira da Silva PUCRS, RS, Brasil

Rosa Maria Rigo

PUCRS, RS, Brasil

ISSN 2179-8435

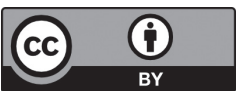

A matéria publicada neste periódico é licenciada sob forma de uma Licença Creative Commons - Atribuição 4.0 Internacional. http://creativecommons.org/licenses/by/4.0/
RESUMO: O presente artigo propõe a uma reflexão acerca da prática docente nos anos iniciais sobre um recorte a partir de pesquisa realizada com uma professora que atua com $4^{\mathrm{O}}$ e $5^{\mathrm{O}}$ anos do ensino fundamental a qual trabalha com a disciplina de Filosofia. Apresenta-se a análise de resultados parciais sobre essa prática docente compreendendo que os registros dos Diários de Aula contribuem significativamente no processo de reflexão docente sobre sua prática pedagógica. Os dados foram obtidos a partir dos registros dos diários de aula da professora. A metodologia é de cunho qualitativo e a proposta foi que a professora escrevesse seus diários de aula após ter tido os esclarecimentos na perspectiva de Zabalza (2004).

Palavras-chave: Diários de Aula. Formação de Professores. Reflexão docente. Educação Básica.

ABSTRACT: This article proposes a reflection on the teaching practice in the initial years of a clipping from research conducted with a professor who plays with 4 and 5 years of elementary school which works with the discipline of Philosophy. The analysis of partial results about this teaching practice understanding that Daily records of school contribute significantly in the process of teaching reflection about their pedagogical practice. The data were obtained from the records of the class teacher diaries. The methodology is of qualitative nature and the proposal was that the teacher wrote his diaries after classrooms have had clarifications from the perspective of Zabalza (2004).

Keywords: Class journals. Teacher training. Teaching reflection. Basic Education. 
Os diários contribuem de uma maneira notável para o estabelecimento dessa espécie de círculo de melhoria capaz de nos introduzir em uma dinâmica de revisão e enriquecimento de nossa atividade como professores.

(ZABALZA, 2004)

\begin{abstract}
epígrafe nos remete a pensar sobre a relevância que os registros dos diários de aula apresentam no que tange às mudanças na prática docente. Conforme o autor já menciona, os diários de aula oportunizam o professor a inserir-se em um contexto de reflexão sobre o que faz, podendo assim redimensionar e qualificar sua ação pedagógica.

A prática reflexiva no exercício da docência nem sempre se faz presente. Para tanto, pode-se pensar em inúmeros fatores, excesso de carga horária de trabalho que gera falta de tempo, a prática reflexiva sobre o trabalho não fazer parte do seu cotidiano, entre outros. Na perspectiva de Zabalza (2004), uma possibilidade para o docente realizar reflexões sobre sua prática pedagógica seria através do registro dos Diários de Aula. Registro esse, que o professor realiza sem uma rigorosidade de frequência, podendo ser diário, semanal ou quinzenal, na medida em que sentir a necessidade de escrever sobre seus sentimentos e percepções acerca de seu trabalho, de sua prática pedagógica em sala de aula.

Esse artigo surge a partir de experiências realizadas ao longo de um semestre em que se deu a coleta de dados para análise da dissertação de mestrado em educação na linha de Pesquisa Formação, políticas e práticas em educação do Programa de Pós-Graduação da PUCRS. Os Diários de Aula, na perspectiva de Zabalza (2004), ocupam lugar central na investigação, sendo utilizados como instrumento de reflexão docente sobre as práticas pedagógicas bem como recurso de qualificação na escrita dos professores.

O objetivo da escrita deste artigo é verificar, a partir das análises dos diários de aula os aspectos objetivos e os aspectos subjetivos subjacentes nos registros da professora de filosofia de $4^{\circ}$ e $5^{\circ}$ anos do ensino fundamental. Desta forma, lança-se o olhar sobre as dimensões pedagógicas bem como aspectos subjetivos envolvidos nessa escrita, a fim de estabelecer uma reflexão sobre a prática diária em sala de aula.

Evidenciou-se no decorrer da pesquisa que a professora em questão já realizava algumas anotações sucintas ao final das aulas como forma de catarse. Mas não os compreendia como registros de diários conforme a perspectiva atribuída por Zabalza (2004).
\end{abstract}




\section{Percursos metodológicos deste estudo}

Este estudo foi desenvolvido na perspectiva da abordagem qualitativa, pois esta permite buscar a compreensão de um problema que não se compõe de forma objetiva. Os dados foram coletados a partir dos registros dos Diários de Aula feitos pela professora de Filosofia dos $4^{\mathrm{O}}$ e $5^{\mathrm{O}}$ anos do ensino fundamental.

Claro está, que anterior à coleta dos diários de aula propriamente ditos, houve um momento específico com a professora para fins de explanação da proposta do estudo e a devida autorização da professora, utilizando o Termo de Consentimento Livre e Esclarecido. Na sequência foi explicado sobre o que são os diários de aula, na perspectiva de Zabalza (2004) para então a professora efetivamente dar início aos seus registros. Os diários de aula foram recolhidos semanalmente, ao longo de dois meses, sem ter a sistematização de ser diariamente para assim evitar um certo engessamento da proposta. Cabe ainda destacar que os excertos retirados dos diários de aula foram trazidos em itálico ao longo do texto como forma de ilustrar os argumentos apresentados, sendo que tais excertos são postos em diálogo permanente com os teóricos da área bem como as inferências elaboradas pela pesquisadora.

\section{Refletindo sobre a prática docente e os registros dos Diários de Aula}

A prática dos registros por parte dos professores, conforme já citado, pode ser considerado algo novo, ou seja, algo não muito presente no cotidiano dos professores no século XXI. São poucos os que têm uma prática reflexiva sobre seu trabalho. O que se ouve mais comumente é o registro que cada professor faz sobre fatos, aspectos da aprendizagem, evolução e avaliação dos alunos. Ou seja, são dados importantes na medida em que ao final de um trimestre necessitam escrever o parecer descritivo ou relatório de avaliação.

Essa pouca ou nenhuma reflexão sobre sua prática docente pode estar atribuída por vezes pela falta de tempo em que este se encontra. Atuando dois turnos e em alguns casos ainda buscando graduar-se, faz com que seu tempo realmente seja restrito. Com isso, segundo Herbertz e Vitória (2010, p. 39) "as condições para se aprimorar profissionalmente e a necessidade absoluta de assumir a educação continuada como princípio/valor profissional" ficam relegados a um segundo plano.

Nesse sentido, acredita-se que a formação continuada deve ser uma constante na vida e prática do profissional da educação. A educação de maneira contínua e permanente é que pode apresentar melhorias no contexto educacional em nosso país. Assim, o professor terá maiores condições e possibilidades em "ajudar o aluno a conquistar, com seus próprios recursos intelectuais e afetivos, uma sólida aprendizagem de conhecimentos, habilidades, valores" (LIBÂNEO, 2009, p. 6). 
Pensando a realidade escolar do século XXI, não se pode esquecer de mencionar que os alunos que temos hoje nas escolas não são aqueles que aceitam qualquer proposta ou atividade. Os alunos de hoje, independente da faixa etária, se posicionam criticamente questionando os porquês, não realizando as atividades propostas ou até mesmo evadindo da escola. Muitas vezes o professor idealiza um tipo de aluno que na prática não existe. Sonha com aquele aluno comportado, que atende a todas as solicitações e realiza tudo o que é proposto em aula. Quando isso não acontece, há certa frustração e até mesmo pode-se dizer, um mal estar docente.

Desta forma, cabe salientar da importância dada à formação continuada para ter espaço de troca entre docentes, relatos de experiências docentes, discussões acerca de textos para reflexão, estudo de caso, registro de diários de aula. Pois se entende que o professor hoje deve voltar-se para um trabalho de transformação e não de reprodução. Para Herbertz e Vitória (2010, p. 39), “[...] será inevitável que entendamos a aprendizagem do futuro professor como resultante da sua própria atividade intelectual". E nessa perspectiva os professores devem caminhar, uma vez que toda prática docente deve estar alicerçada em pressupostos teóricos.

É imprescindível que seja dada a devida atenção aos aspectos de formação docente no que se refere às dimensões pedagógicas, ou seja, sobre os aspectos de aprendizagem. Há que se considerar o aluno como um ser holístico, com suas condições socioeconômicas e culturais, seu contexto histórico, sua história vital, suas idéias, seus sonhos, suas aspirações, seus sentimentos. Conforme Libâneo, (2009, p. 8), "toda aprendizagem precisa ser significativa, isto é, os conteúdos precisam fazer sentido para o aluno, com base nos próprios sentidos que os alunos atribuem ao que estão aprendendo".

Considerando que a formação continuada dos professores não se dá apenas em eventos oficiais como congressos, seminários, palestras, oficinas, pode-se pensar que toda prática em que se faz presente a reflexão e a discussão acerca de uma teoria ou realidade vivida também poderá contribuir significativamente para um crescimento pessoal e profissional. Sobre a importância da reflexão docente, Bolzan $(2009$, p. 17) afirma que "refletir sobre o saber e o saber-fazer implica processos racionais e intuitivos, e esses processos, por sua vez, fazem parte do pensamento prático do professor". Portanto, escrever sobre sua prática e refletir sobre a mesma, é um excelente exercício, inclusive para qualificar a escrita.

Destaca-se, portanto, a relevância e necessidade de possibilitar, a partir dos diários de aula, espaço para que se possa rever e refletir sobre tudo o que subjaz no fazer docente e sobre si enquanto pessoa, uma vez que se entende que os sentimentos e emoções acompanham o ser humano em todos os momentos de sua vida, sejam eles de ordem pessoal ou profissional.

Ao registrar, o professor já realiza uma espécie de catarse sobre si mesmo. Ao reler essa escrita, reorganiza seu pensamento e analisa os aspectos relevantes e aquilo que precisa ser eliminado e reconstruído em sua prática na sala 
de aula. O registro, no nosso entendimento, tem uma dupla função: ser um espaço de desabafo com o diário e também abre caminhos para posteriores reflexões a partir das retomadas feitas. Para Bolzan (2009, p. 17):

[...] ao refletir, ele passa a pensar sobre a situação passada, estabelecendo relações com situações futuras de ensino que virá propor e organizar. Esse processo de reflexão crítica, feito individualmente ou em grupo, pode tornar conscientes os modelos teóricos e epistemológicos que se evidenciam na sua atuação profissional e, ao mesmo tempo, favorecer a comparação dos resultados de sua proposta de trabalho com as teorias pedagógicas e epistemológicas mais formalizadas.

A escrita e a análise dos diários de aula revelam pontos peculiares que podem ajudar os professores a remeter um olhar sobre si e sobre seu profissionalismo, tornando assim a educação como um todo, portanto mais ética e mais qualificada. A reflexão docente, a partir dos registros dos diários de aula, permite um distanciar-se daquilo que faz em aula e em outro momento retorna para reler e com isso depurar sua prática docente Zabalza (2004).

Nos registros dos diários de aula analisados, evidenciam-se as dimensões pedagógicas: o planejamento, o ensino, a aprendizagem e a avaliação. Sobre o planejamento é possível identificar no diário em que a professora escreve: "Nesta aula queria que ao final percebessem o quanto cada pessoa é importante" e "[...] realizaram a atividade com vontade [...]". Nesses excertos ainda pode-se destacar outro fator apontado pela professora o qual pode ser avaliado como um aspecto subjetivo que é em relação à individualização dos alunos, fazendo-os pensar sobre sua importância enquanto seres humanos e pertencentes àquela sala de aula. Valoriza enfatizando a forma como os alunos receberam a proposta da aula, segundo o olhar docente, "com vontade".

Pode-se então pensar que há um envolvimento que transcende apenas o fazer docente, mas que também se percebe uma preocupação com o processo de ensino e de aprendizagem dos envolvidos. "Ambas as turmas conseguiram expressar-se bem quanto às questões vividas [...]" segue no mesmo diário escrevendo "[...] vi suas dificuldades em casa e com a conversa pensamos em como driblar esses episódios".

No excerto acima, pode-se refletir sobre a questão do vínculo afetivo estabelecido entre professora e alunos, o espaço que os alunos têm para refletir e conversar sobre diferentes temáticas e aspectos da vida cotidiana. Enfim, é um momento para pensar. Um pensar individual e compartilhado no coletivo. Assim, se estabelece um bem-estar docente e discente. Sem dúvida a construção da aprendizagem de cada um tem outra conotação e significado. Pois há espaço de catarse e elaboração das "mazelas corporais".

A professora enfatiza a satisfação dos alunos pela aula de filosofia e conseqüentemente também a sua realização profissional, na medida em que relata em seus registros que "no recreio foi possível perceber a satisfação, pois se 
ouvia comentários da aula e como estavam gostando da aula". Em outro diário, aparece o aspecto subjetivo, ainda aponta nessa mesma perspectiva afirmando "fui para casa realizada".

Seria a dinâmica da aula responsável por essa satisfação discente? Houve um olhar sobre a turma e valorizadas suas peculiaridades? O excerto a seguir possivelmente responde aos questionamentos. "A diretora até comentou na sala dos profes que no ano anterior os alunos reclamavam de só copiar coisas do quadro e eu apareci com aulas dinâmicas eles estavam muito satisfeitos". Na perspectiva de Tardif (2008), pode-se pensar que o trabalho docente é permeado de afetividade e de emocional e ressalta que o trabalho docente se baseia "na capacidade não somente de pensar nos alunos, mas igualmente de perceber e de sentir suas emoções, seus temores, suas alegrias [...]" (p. 130).

Nesse sentido, a professora possibilita atividades em que os alunos são os autores, e que eles precisam exercitar sua autonomia. Isso se evidencia no registro a seguir "[...] eles tiveram que escolher um tema e criar uma história em quadrinhos [...]" tal foi o processo de autonomia e sensibilidade dos alunos que a escolha do tema surpreendeu a professora, conforme segue o registro "[...] me chamou a atenção a turma 522 quase $80 \%$ da turma escolheu o tema AMOR-AMIZADE" no entanto "já a turma 521 foi $90 \%$ PERDÃO [...]".

Tal se pode observar que cada turma teve sua autonomia para escolher aquilo que realmente lhes fazia sentido debater e trabalhar. A proposição do trabalho pedagógico que pode ser destacado é a flexibilidade em redirecionar o planejamento de acordo com a necessidade diante do que os alunos trazem do seu contexto para dentro da sala de aula.

O princípio de toda atividade que envolva o planejamento é a vontade de querer mudar, qualificar a ação pedagógica e acima de tudo proporcionar uma aprendizagem significativa ao aluno. De acordo com Loch (2009, p. 22), "é importante planejar pesquisando sobre a vida [dos alunos] tornando-os também autores e participantes do planejamento, ao incorporar ao currículo os processos históricos, culturais, políticos, sociais e econômicos que constituem o seu tempo, as contradições presentes na sociedade".

Nesse sentido pode-se trazer outro excerto do registro da professora ao escrever que "[...] preciso estar o tempo todo atrás de outras atividades pois a cobrança dos alunos é muito grande [...]". Denota-se o quanto há uma preocupação docente em levar para a sala de aula propostas que sejam interessantes e promovam a participação, a reflexão e a aprendizagem.

Ressignificar o planejamento se faz necessário na prática docente uma vez que se trabalha com o aluno real. Para que haja esse redimensionamento no planejar do professor torna-se imprescindível ter "espaços de reflexão sobre o planejado durante o ano: o que está dando certo, o que está tendo dificuldade, que mudanças podem ser feitas" (VASCONCELLOS, 2004, p. 150).

Um dos desafios posto à escola é proporcionar espaços de reflexão sobre o sentido do planejamento. Essa análise só é possível quando o professor efetivamente tiver espaço para esse fim. Quando há na escola momentos em que haja 
discussão, trocas entre seus pares e um planejar de forma integrada com todas as áreas do conhecimento, há também uma prática coerente na sala de aula.

A dimensão da avaliação também é evidenciada na escrita dos diários de aula da professora quando escreve "[...] consigo sentir ao final de cada aula o conhecimento que absorveram durante a aula". Na medida em que o professor interioriza e muda a concepção acerca da avaliação, compreendendo sua real função e intencionalidade, é possível pensar que ao organizar e executar seu planejamento, estará pensando e levando em consideração as reais necessidades de seus alunos. Assim, fará também de sua avaliação um processo contínuo de reflexão sobre o contexto escolar. Na perspectiva da avaliação mediadora, Hoffmann (1993) aponta que se faz necessário

[...] analisar teoricamente as várias manifestações dos alunos em situação de aprendizagem (verbais ou escritas, outras produções), para acompanhar as hipóteses que vem formulando a respeito de determinados assuntos, em diferentes áreas de conhecimento, de forma a exercer uma ação educativa que lhes favoreça a descoberta de melhores soluções ou a reformulação de hipóteses preliminarmente formuladas. (p. 96)

A avaliação, portanto, não se restringe a determinados fragmentos do processo, mas sim à totalidade do ensino e aprendizagem. A avaliação tem o objetivo de melhorar a ação educativa, afinal avaliar faz parte deste procedimento e, por este motivo, não se aplica apenas ao momento no qual o aluno se encontra, mas também no qual se encontra o professor.

Considerando a perspectiva que esse estudo assume, pode-se dizer que o trabalho docente, além dos aspectos objetivos tem presente aspectos subjetivos, ou seja, de realização e/ou frustração profissional, o que algumas teorias trazidas, sobretudo, pela Psicologia Positiva denominam de bem-estar e mal-estar docente (MOSQUERA, 1996). Nesse sentido, os registros da professora evidenciam explicitamente tais sentimentos. Ao falar da importância do professor escrever sobre os acontecimentos de sua prática pedagógica, García (2008, p. 126) afirma que: "la competência para escribir, para anotar, para describir, para relatar com palabras escritas emociones, sentimientos, vivencias, interesses, frustraciones, alegrías, com la dificultad que ello implica”, é sem dúvida uma técnica muito importante.

Em toda ação pedagógica mencionada nos diários de aula há uma satisfação ou uma insatisfação em relação ao ofício do professor. Está presente nos diários da professora, o desejo docente em desenvolver nos alunos, através das atividades, a autonomia, autoestima e a autoimagem, além do cognitivo. Tais características evidenciam-se nas 
atividades propostas na turma do $5^{\mathrm{o}}$ ano, quando tinham que se organizar em grupos e realizar de um trabalho para posterior apresentação em aula. E a autonomia dos alunos aparece em eles realizarem as atividades "[...] com mais concentração e facilidade, eles conseguiram se organizar sozinhos nos grupos [...]". Evidencia-se nesse registro, ainda que de maneira implícita, um aspecto subjetivo, a satisfação docente.

Diante da perspectiva de um trabalho pedagógico que privilegie o desenvolvimento de tais aspectos nos alunos, pode-se atribuir e relacionar essa prática ao perfil comprometido, dedicado, responsável com que desempenha sua ação docente em sala de aula junto aos alunos? Para Bolzan (2009, p. 20)

à medida que observamos como os professoras aprendem, podemos compreender porque ensinam desta ou daquela maneira. Seus construtos mentais interferem diretamente nas suas proposições pedagógicas, indicando consequências significativas nas formas de intervenção.

A satisfação docente também se expressa pelo viés do aluno quando the é proporcionado espaço para reconhecimento do outro, de suas qualidades e de suas capacidades. Fato é que "[...] cada um relatou o que o colega tinha de especial e todos ficaram bem felizes" e a professora do 5응 a utiliza as aulas de "filosofia como autoconhecimento [...]" oportunizando a reflexão pessoal em que "[...] pensaram sobre sua vida escolar e familiar". Sobre essa temática, afirma Arroyo $(2005$, p. 217) "o planejamento do tempo deve incluir não somente a realização da ação, mas também a reflexão sobre ela". Podemos inclusive, a partir das palavras do autor, refletir sobre o fato de que alocar tempo para pensar, neste caso, seria tão importante como definir o conteúdo e o método. Nessa mesma direção, Demo (2004, p. 23) afirma:

já não nos interessa a memorização de conteúdos, mas até que ponto nossos alunos sabem pensar, constroem sua autonomia, conseguem pesquisar e elaborar, exercitam o questionamento, argumento, fundamentação. Queremos saber da qualidade formal e política: até que ponto manejam conhecimento e até que ponto sabem o que fazer com tal conhecimento.

Talvez se possa pensar que é nesse momento que entra o papel docente, oportunizando momentos de reflexão e debate acerca das situações cotidianas que ocorrem, fazendo com que haja reconhecimento e valorização de todos independente das peculiaridades individuais e assim, atenuar frustrações discentes e docentes, pois as diversidades é que proporcionam a riqueza nas trocas e nas aprendizagens de cada um. 


\section{Reflexões teóricas sobre os dados da pesquisa}

Embora muito já se tenha discutido e refletido sobre a formação docente, sempre de novo se faz necessário, dada a abrangência e relevância do assunto. E, por entendermos que é uma temática que não se esgota em virtude das inúmeras transformações que vivemos no contexto em que se insere a educação. Os referenciais teóricos apontam que é importante deter o olhar sobre a formação e a prática docente. Tardif (2008) contribui afirmando que certas mudanças são necessárias nas concepções e nas práticas docentes. No ponto de vista do autor:

O que é preciso não é exatamente esvaziar a lógica disciplinar dos programas de formação para o ensino, mas pelo menos abrir um espaço maior para uma lógica de formação profissional que reconheça os alunos como sujeitos do conhecimento e não simplesmente como espíritos virgens aos quais nos limitamos a fornecer conhecimentos disciplinares e informações procedimentais, sem realizar um trabalho profundo relativo às crenças e expectativas cognitivas, sociais e afetivas através das quais os futuros professores recebem e processam esses conhecimentos e informações (p. 242).

O autor aborda a questão dos saberes experienciais. Para ele os saberes experienciais são o conjunto de saberes atualizados, adquiridos e necessários da prática profissional dos professores. Segundo Tardif (2008, p. 53):

Os saberes experienciais adquirem também uma certa objetividade em sua relação crítica com os sabres disciplinares, curriculares e da formação profissional. A prática cotidiana da profissão não favorece apenas o desenvolvimento de certezas experienciais, mas permite também uma avaliação dos outros saberes, através da sua retradução em função das condições limitadoras da experiência.

Pode-se concordar com o autor que na medida em que o professor já tem algum tempo de experiência, consegue relacionar as teorias com a prática, uma vez que conhecimentos teóricos e pedagógicos são essenciais para qualquer atuação que se pretenda qualificada. Nesse sentido, "a experiência provoca, assim, um efeito de retomada crítica (retroalimentação) dos saberes adquiridos antes ou fora da prática profissional" (TARDIF, 2008, p. 53).

Nessa perspectiva, Arroyo $(2005 ; 2009)$ também aponta para a formação docente sob o viés da imagem e autoimagem de si em sua função como profissional professor. Na prática docente, a função pedagógica educativa é um dever para os professores, ofício esse que confronta, interroga com o próprio dever.

É possível encontrar nas práticas escolares a recorrência com que os professores depositam ou questionam o sucesso e/ou fracasso escolar dos alunos em relação ao domínio dos conteúdos, ao invés de incluir-se nesse processo 
de ensino, aprendizagem e avaliação. Conforme Arroyo (2005, p.41), "pensar e mexer com a formação humana é um pensar nossa própria formação, nosso próprio percurso".

Nesse sentido, a mudança sempre foi e sempre será algo de certo modo difícil, pois é preciso desconstruir para construir novamente, ao mesmo tempo desacomoda e faz com que se tenha que investir em algo no qual o professor não tem a certeza dos resultados. Para Garcia, (2005, p. 49):

Parece-nos que para aquelas mudanças que implicam o assumir riscos, inseguranças (pelo menos temporariamente) relativamente à ordem, disciplina e rendimento dos alunos (um novo método de leituraescrita), os professores necessitarão de mais informação e tempo para decidirem introduzi-los. É nestes casos que se fala de resistências à mudança para nos referirmos àqueles factores que dificultam aos professores a implementação de novas actividades e organização do ensino.

Assim sendo, para Arroyo (2005) o dever-ser que acompanha a prática educativa e o professor, requer reflexão, leitura, domínio de teorias e metodologias. Segundo o autor, é necessário "tornar o professor reflexivo, capaz de tematizar práticas, pode ser demasiado racional para captar processos tão surpreendentes como acompanhar a formação da infância e da adolescência" (p. 45).

Para isso, torna-se imprescindível conhecer a realidade dos sujeitos alunos com os quais atua. Compreender e valorizar a realidade na qual estão inseridos faz com que o trabalho pedagógico tome outras perspectivas. Em algumas situações, esse olhar, essa mudança, só acontece na medida em que os professores (re)aprendem o sentido da docência. Nas palavras de Garcia (2005, p. 49), "é necessário entender a mudança e a inovação como um processo de aprendizagem e de desenvolvimento pessoal e profissional no qual os professores se implicam como pessoas adultas".

Nessa perspectiva, podemos trazer os diários de aula como contribuição para esse desenvolvimento pessoal e profissional. Pois na medida em que o professor realiza seus registros nos diários de aula, vai realizando uma espécie de catarse, a qual auxilia na reflexão sobre si e sobre ação pedagógica.

Ao fim e ao cabo, escrever sobre o que se está fazendo como profissional é considerado por Zabalza (2004), como processo importante para a conscientização de sua prática. O fato de registrar a prática permite ao sujeito um distanciamento reflexivo que lhe propicia uma análise crítica sobre seu atuar específico.

A escrita nos diários de aula proporcionam duas dimensões profissionais: o que se vai escrevendo (os fatos) e os progressos que esses e a própria atuação apresentam com o passar do tempo. A propósito disso, referendamos essa ideia de Zabalza (2004): 
Os diários contribuem de uma maneira notável para essa espécie de círculo de melhoria capaz de nos introduzir em uma dinâmica de revisão e enriquecimento de nossa atividade como professores. Esse círculo começa pelo desenvolvimento da consciência, continua pela obtenção de uma informação analítica e vai se sucedendo por meio de outra série de fases, a previsão da necessidade de mudanças, a experimentação das mudanças e a consolidação de um novo estilo pessoal de educação. (p. 11)

Nesse sentido, os diários podem ser usados com o objetivo investigativo ou para o desenvolvimento pessoal e profissional dos professores. Eles servem como acesso ao mundo pessoal de cada professor através da revisão de elementos pessoais. Auxiliam também na explicitação dos dilemas que podem ser específicos e decorrentes de situações problemáticas no desenvolvimento da aula. Em síntese, pode-se dizer que somos o que escrevemos. E os diários de aula servem para depurar e qualificar a prática profissional docente.

\section{À guisa de conclusão}

A partir das reflexões aqui trazidas é possível pensar que os diários de aula auxiliam significativamente no trabalho pedagógico dos professores. Contribuem no momento em que este pode registrar o que aconteceu no decorrer de suas aulas, bem como falar de seus sentimentos. Pois se sabe o quanto sentimentos de satisfação e de frustração (aspectos subjetivos) se fazem presentes no dia a dia de sala de aula. E em alguns casos os docentes não têm com quem dialogar.

Cada vez que o professor realiza seus registros pode-se considerar como uma forma de desabafo, de catarse e ao retornar a essa escrita, podendo reler o que registrou, possibilita uma reflexão maior no sentido de reestruturar seu planejamento, sua ação pedagógica e ter um novo olhar sobre todo o processo educativo. Nesse sentido, os registros são ferramentas de qualificação pessoal e profissional.

A professora, sujeito desta investigação, já tinha a prática de registrar os fatos ocorridos em aula com os alunos e sobre seus sentimentos vividos em sua prática. Logicamente que não os denominava conforme propõe Zabalza (2004). Todavia sua prática é pautada no respeito na relação professor-aluno, bem como na valorização individual de cada sujeito e seu processo de aprendizagem. Acredita-se que a prática da professora investigada se qualificará ainda mais na medida em que utilizará os registros com o sentido pedagógico e assim possibilitará o redimensionamento de seu fazer docente. 


\section{Referências}

ARROYO, M. G. Oficio de mestre: imagens e auto-imagens. Petrópolis, RJ: Vozes, 2000.

ARROYO, M. G. Imagens quebradas: trajetórias e tempos de alunos e mestres. Petrópolis, RJ: 2005.

BOLZAN, D. P. V. Formação de professores: compartilhando e reconstruindo conhecimentos. Porto Alegre: Mediação, 2009.

DEMO, Pedro. Ser professor é cuidar que o aluno aprenda. Porto Alegre: Mediação, 2004.

GARCÍA, C. M.. Formação de professores: para uma mudança educativa. Trad. Isabel Narciso. Porto, Portugal: Porto, 2005.

GARCÍA, Carlos H. Bienestar docente y pensamiento emocional. Madrid: Wolters Kluwer España, 2008.

HERBERTZ, D., VITORIA, M. I. C. Os diários de aula como possibilidade de qualificação profissional dos professores em formação no ensino superior. Revista Prâksis, Feevale, ano VII, v. 1, p. 37-44, jan. 2010.

HOFFMANN, J. M. L. Avaliação mediadora: uma prática em construção da pré-escola à universidade. Porto Alegre: Educação \& Realidade, 1993.

HOFFMANN, J. M. L. Avaliar: respeitar primeiro, educar depois. Porto Alegre: Mediação, 2008.

LIBÂNEO, J. C. O ensino de graduação na Universidade: a aula universitária. 2009. Disponível em: <http://www.ucg.br/site_docente/ edu/libaneo/pdf/ensino/pdf>. Acesso em: 19 maio 2014.

LOCH, J. M. de P. et al. EJA: planejamento, metodologias e avaliação. Porto Alegre: Mediação, 2009.

MOSQUERA, Juan J. M., STOBÄUS, Claus. O mal-estar na docência: causas e conseqüências. In: Educação, Porto Alegre: PUCRS, ano XIX, n. 31, 1996.

PERRENOUD, P. Práticas pedagógicas, profissão docente e formação. Perspectivas sociológicas. Lisboa: Dom Quixote - Instituto de Inovação Educacional, 1993.

PERRENOUD, P. A prática reflexiva no ofício de professor: profissionalização e razão pedagógica. Trad. Cláudia Schilling. Porto Alegre: Artmed, 2002.

PERRENOUD, P. et al. As competências para ensinar no século XXI: a formação dos professores e o desafio da avaliação. Trad. Cláudia Schilling e Fátima Murad. Porto Alegre: Artmed, 2002.

SCHÖN, D. A. Educando o profissional reflexivo: um novo design para o ensino e a aprendizagem. Porto Alegre, RS: Artes Médicas Sul, 2008.

TARDIF, M. Saberes docentes \& formação profissional. 9. ed. Petrópolis, RJ: Vozes, 2008.

TARDIF, M.; LESSARD, C. O trabalho docente: elementos para uma teoria da docência como profissão de interações humanas. Tradução de João Batista Kreuch. 3. ed. Petrópolis, RJ: Vozes, 2007.

VASCONCELLOS, C. S. Avaliação da aprendizagem: práticas de mudança - por uma práxis transformadora. 9. ed. São Paulo: Libertad, 2008. 
VASCONCELLOS, C. S. Planejamento: Projeto de Ensino-Aprendizagem e Projeto Político-Pedagógico. 7. ed. São Paulo: Libertad, 2004.

XAVIER, M. L.M. et al. Planejamento em destaque: análises menos convencionais. Porto Alegre: Mediação, 2000.

ZABALZA, M. A. Diários de Aula: um instrumento de pesquisa e desenvolvimento profissional. Porto Alegre: Artmed, 2004.

ZABALZA, M. A. O ensino universitário: seu cenário e seus protagonistas. Porto Alegre: Artmed, 2004.

\section{Endereço para correspondência:}

Dirce Hechler Herbertz

Rua Guanabara, 678

93320-220 Novo Hamburgo, RS, Brasil

E-mail:<dhtz@hotmail.com>

Recebido em: abril/2014

Aceito em: maio/2014 